SOSIOLIUM

\title{
PERAN PEMBELAJARAN ILMU PENGETAHUAN SOSIAL DALAM UPAYA PENCEGAHAN RADIKALISME DI MTS NU TBS KUDUS
}

\author{
Muhammad Hilmi H, Fredy Hermanto \\ Prodi Pendidikan Ilmu Pengetahuan Sosial, Fakultas Ilmu Sosial, Universitas Negeri Semarang, Indonesia
}

\begin{tabular}{l}
\hline Info Artikel \\
\hline Sejarah Artikel: \\
Disubmit: Juli 2021 \\
Direvisi: Agustus 2021 \\
Diterima: September \\
2021 \\
\hline Keywords: \\
Radicalism, \\
Strengthening Character \\
Education (PPK), Social \\
Education
\end{tabular}

\begin{abstract}
Sari
Penelitian ini bertujuan untuk mengetahui upaya pencegahan radikalisme di sekolah melalui penguatan karakter didalam pembelajaran ilmu pengetahuan sosial (IPS) dan pengimplementasian penguatan pendidikan karakter (PPK) didalam kegiatan ekstrakulikuler di MTS NU TBS Kudus. Hasil penelitian menunjukkan bahwa sekolah berupaya mencegah berkembangnya radikalisme. Pencegahan Radikalisme di sekolah dilaksanakan melalui pengimplementasian PPK melalui tiga kegiatan yaitu kegiatan intrakulikuler, kegiatan kokulikuler, dan kegiatan ekstrakulikuler. Pengimplementasian didalam kegiatan intrakulikuler berfokus pada pembelajaran IPS yang memiliki materi serta dimensi yang berkaitan dengan kehidupan sehari-hari. Pengimplementasiaan didalam kegiatan ekstrakulikuler berfokus pada implementasi visi misi melalui budaya sekolah dan kegiatan sekolah. Sedangkan hasil analisis upaya pencegahan radikalisme melalui implementasi penguatan karakter menunjukkan bahwa pengimplementasian PPK sudah dilaksanakan dan memberikan dampak, namun dalam pelaksanaanya masih menemui sejumlah kendala terlebih dimasa pandemi Covid-19.
\end{abstract}

\begin{abstract}
This study aims to determine efforts to prevent radicalism in schools through strengthening character in social science learning (IPS) and implementing strengthening character education (PPK) in extracurricular activities at MTS NU TBS Kudus. The results showed that schools were trying to prevent the development of radicalism. Prevention of radicalism in schools is carried out through the implementation of strengthening character education (PPK) through three activities, namely intracular activities, co-curricular activities, and extracurricular activities. Implementation in intraculricular activities focuses on social studies learning which has material and dimensions related to everyday life. Implementation in extracurricular activities focuses on implementing the vision and mission through school culture and school activities. Meanwhile, the results of the analysis of efforts to prevent radicalism through the implementation of character strengthening show that the implementation of PPK has been carried out and has had an impact, but in its implementation there are still a number of obstacles, especially during the Covid-19 pandemic.
\end{abstract}

(C) 2021 Universitas Negeri Semarang

\footnotetext{
Alamat korespondensi:

Gedung C1 Lantai 1 FIS Unnes

Kampus Sekaran, Gunungpati, Semarang, 5022

Email: fredyhermanto@mail.unnes.ac.id
}

E-ISSN 2685-4929 


\section{PENDAHULUAN}

Asrori Ahmad (2015) menyebutkan bahwa keberadaan penolakan dan tuntutan akan perubahan secara menyeluruh dan cepat melalui gerakan radikal atau keras tersebut kemudian disebut sebagai sebuah radikalisme. Radikalisme memiliki beberapa artian dalam konteks yang berbeda, dalam konteks terminologis radikalisme merupakan sebuah paham yang menuntut cara berpikir dalam menghadapi sesuatu secara mendalam atau hingga ke akar-akarnya. Sementara dalam konteks politis, radikalisme diartikan sebagai sebuah paham yang menuntut perubahan secara menyeluruh dan cepat terhadap suatu tatanan nilai, sistem politis yang dianggap mapan dengan nilai lain yang dianggap jauh lebih baik. Radikalisme dalam konteks keagamaan diartikan sebagi paham keagaaman yang mengacu pada pemahaman agama sangat mendasar dengan fanatisme yang sangat tinggi.

Undang-Undang No.20 tahun 2003 mengenai Sistem Pendidikan Nasional mengisyaratkan tujuan pendidikan nasional dimana membentuk manusia yang beriman dan bertakwa kepada Tuhan Yang Maha Esa, berakhlak mulia, dan menajdi warga Negara yang demokratis serta bertanggung jawab. Namun berbanding terbalik dengan tujuan pendidikan dimana ditemui adanya radikalisme dalam dunia pendidikan tidak dapat dipungkiri hal ini didasarkan atas survei yang dilakukan oleh Lembaga Kajian Perdamaian (LaKIP) dimana menyebutkan bahwa survei yang dilakukan pada bulan Oktober 2010 hingga Januari 2011 hampir 50 persen peserta didik setuju tindakan kekerasan atau aksi radikal demi agama. Lebih mencegangkan lagi ketika 25,8 persen peserta didik menganggap pancasila sudah tidak relevan sebagai ideologi negara. Survei tersebut dilakukan di 59 sekolah swasta dan 41 sekolah negeri serta menggunakan sampel samapi 993 siswa pada tingkat SMP dan SMA.

Moh. Hasim (2015) menyebutkan bahwa ada beberapa materi keagamaan yang jika tidak disampaikan dan diberi pemahaman lebih lanjut oleh guru memiliki tingkat kerawanan dalam penafsiran dan pemahaman dikalangan pelajar yang seakan mengajarkan mengenai radikalisme keagamaan. Keberadaan radikalisme menjadi salah satu "PR" dalam dunia pendidikan dan menjadi bukti belum sepenuhnya tujuan dari pendidikan tercapai. Pembelajaran Agama belum sepenuhnya berhasil mencegah berkembangnya radikalisme. Pembelajaran lainya perlu memberikan dukungan dalam pencegahan radikalisme sesuai dengan ranah pembelajaran masing-masing dan tidak terkecuali pembelajaran IPS.

Pembelajaran IPS yang seharusnya mampu membentuk manusia yang memiliki jiwa sosial, peduli sesama, dan sebagainya. Pembentukan dan pengembangan kognitif, psikomotorik dan afektif dapat dilaksanakan melalui proses pembelajaran dan kegiatan lainnya yang mendukung. Aspek afektif peserta didik dapat dibentuk melalui penanaman karakter yang tersirat dalam proses pembelajaran yang sebelumnya sudah direncanakan didalam Rancangan Proses Pembelajaran (RPP). Penanaman karakter menjadi hal yang wajib dizaman sekarang melihat berbagai permasalahan sosial yang terjadi di masyarakat.

Pentingnya moral dan karakter menjadi salah satu konsen pemerintah, melalui Perpres Nomor 87 Tahun 2017 pemerintah menjawab tantangan degradasi moral sampai radikalisme melalui dunia pendidikan. progam tersebut dikenal dengan penguatan pendidikan karakter (PPK). Implementasinya PPK dalam pendidikan formal diitegrasikan melaui tiga kegiatan yaitu kegiatan intrakulikuler, kokulikuler, dan ekstrakulikuler. PPK memfokuskan ada 5 karakter utama dimana kelima karakter tersebut diharapkan dapat menjawab berbagai permasalahan yang ada dan tidak terkecuali permasalahan radikalisme.

Berdasarkan latar belakang tersebut, peneliti berfokus dalam mengetahui: 1 . strategi Sekolah dalam progam penguatan pendidikan karakter (PPK) dalam upaya pencegahan radikalisme; 2. perspektif guru di Sekolah mengenai radikalisme; 3 . bentuk pelaksanaan pencegahan radikalisme melalui pembelajaran IPS di Sekolah.

\section{METODE}

Penelitian ini merupakan penelitian kualitatif, yaitu penelitian yang digunakan untuk meneliti pada kondisi obyek alamiah, teknik pengumpulan data dilakukan secara triangulasi, analisis data bersifat induktif, dan hasil penelitian lebih menekankan makna daripada generalisasi (Sugiyono, 2016). Lokasi penelitian dilakukan di MTS NU TBS Kudus yang terletak di jalan KH. Turaichan Adjhuri 23, Desa Kajeksan, Kecamatan Kota, Kabupaten Kudus.

Fokus penelitian ini adalah peran IPS didalam upaya pencegahan radikalisme melalui pengimplementasian progam PPK di MTs NU TBS Kudus. Sumber data dalam penelitian ini 
dibedakan menjadi 2 yaitu sumber data primer dan sumber data sekunder. Sumber data primer dalam penelitian ini diperoleh dengan melaksanakan wawancara kepada wakil kepala bidang kurikulum, guru IPS, wali murid, peserta didik. Sedangkan data sekunder ini diperoleh melalui melalui pengkajian bahan ajar berupa kurikulum, buku-buku, jurnal, peraturan perundang-undangan, dan dokumen terkait. Teknik pengumpulan data dilakukan dengan teknik triangulasi. Pada penelitian ini menggunakan triangulasi teknik. Teknik analisi data dalam penelitian ini meliputi pengumpulan data, reduksi data, penyajian data dan penarikan simpulan.

\section{HASIL DAN PEMBAHASAN}

Penelitian ini dilaksanakan di MTs NU Tasywiquth Thullab Salafiyyah (TBS) terletak di kecamatan Kota, kabupaten Kudus lebih tepatnya terletak di jalan KH. Turaichan Adjhuri 23, Desa Kajeksan, Kecamatan Kota, Kabupaten Kudus. Keberadaan radikalisme yang merambah duni pendidikan menjadi sebuah permasalahan, bersumber dari survei yang dilakukan oleh LaKIP terdapat sejumlah peserta didik yang dirasa sudah terpapar radikalisme. Mengetahui hal tersebut, perlu diketahui lebih lanjut bagaimana proses pencegahan radikalisme yang dilakukan oleh sekolah.

\section{Strategi Sekolah dalam Penguatan Karakter Peserta Didik dan Menghadapi Tantangan Mengenai Keberadaan Radikalisme Yang Berkembang}

visi misi di MTs NU Tasywiquth Thullab Salafiyyah (TBS) terdapat sejumlah tujuan dan pelaksanaan tujuan tersebut. Tujuan sekolah dimana tertuang didalam visi sekolah dimana sekolah berfokus untuk mencetak generasi yang cerdas dalam iptek dan santun dalam beragama serta kuat dalam imtaq. Terdapat enam Poin yang menjadi misi dari MTs NU Tasywiquth Thullab Salafiyyah (TBS), keenam poin tersebut menjadi representasi dari visi yang dirumuskan sekolah yang menunjukkan tindakan dari bagaimana sekolah mewujudkan visi yang diharapkan. Pelaksanaan visi misi tersebut tertuang didalam sejumlah kegiatan dan budaya sekolah dimana menjadi salah satu nilai lebih dari sekolah. Visi misi juga diharapkan dapat menjadi sebuah identitas sekolah sehingga membedakan dengan sekolah lainnya.

Berdasarkan Peraturan Menteri

Pendidikan Nasional (Permendiknas) Republik Indonesia Nomor 39 Tahun 2009 tentang pembinaan peserta didik mengartikan kegiatan ekstrakurikuler merupakan salah satu jalur kegiatan yang berfokus pada pembinaan peserta didik. sejumlah kegiatan sekolah yang menarik untuk dikaji lebih mendalam baik secara dampak terhadap penguatan karakter, kegiatan tersebut diantaranya hafalan alaliyah, dakwah kelas, ziarah, dan kegiatan hari santri nasional. kegiatan sekolah yang dipaparkan didalam hasil penelitian juga menunjukkan adanya penguatan karakter sesuai dengan Peraturan Presiden (Perpres) Nomor 87 Tahun 2017 dimana pelaksanaan PPK dapat diintegrasikan melalui kegiatan ekstrakurikuler. Pelaksanaan tersebut diharapkan mampu menunjang ketercapaian sejumlah karakter yang diharapkan dan mampu menjadi salah satu cara mencegah beragam permasalahan yang timbul akibat kurangnya karakter dalam diri peserta didik seperti radikalisme dalam sudut pandang agama.

Menurut Aan Komariah dan Cepi (2010) mengartikan budaya sekolah merupakan kepribadian organisasi yang membedakan antara satu sekolah dengan sekolah lainnya, bagaimana seluruh anggota organisasi sekolah berperan dalam melaksanakan tugasnya tergantung pada keyakinan, nilai dan norma yang menjadi bagian dari budaya sekolah tersebut. budaya sekolah yang diterapkan di MTs NU Tasywiquth Thullab Salafiyyah (TBS) dimana budaya yang ada mengacu kepada sejumlah nilai yang ada didalam agama Islam terlebih dari organisasi keagamaan Nahdlatul Ulama (NU). Beberapa budaya tersebut seperti ash sidqu (jujur), Al amanah (dapat dipercaya baik dalam ucapan dan tindakan), Al adalah (adil itu bukan sama rata tapi sesuai porsinya), ta'awun ( tolongmenolong)Istiqomah (konsisten). Nilai-nilai tersebut sejalan dengan karakter utama yang terdapat didalam penguatan pendidikan karakter (PPK) dimana berfokus kepada lima karakter utama dan integrasi kedalam kegiatan intrakurikuler, kokulikuler, dan ekstrakulikuler yang mengacu pada Peraturan Presiden (Perpres) Nomor 87 Tahun 2017.

MTs NU Tasywiquth Thullab Salafiyyah (TBS) menjawab tantangan pencegahan radikalisme dapat melalui sejumlah cara guna mencegah berkembangnya radikalisme. Bentuk pencegahan radikalisme yang berkembang ditunjukkan melalui sejumlah kegiatan disekolah dimana kegiatan tersebut berguna untuk membentuk karakter peserta didik sehingga dapat menjadi teladan bahwa melalui sejumlah karakter yang diajarkan dapat menjadi solusi pencegahan radikalisme. 
Pandangan Guru Mengenai Radikalisme radikalisme dapat diartikan menjadi 2 artian dasar yaitu, pertama radikalisme diartikan sebagai paham keagamaan yang kaku dan tidak menghargai adanya pluralitas sehingga membuat dirinya merasa paling benar (klaim kebenaran tunggal), kedua radikalisme diartikan sebagai paham politis yang bertentangan dengan ideologi atau sistem yang berlaku dan menginginkan adanya perubahan. Adanya perbedaan pendapat mengenai artian radikalisme baik dalam sudut pandang keagamaan ataupun politis perlu disatukan agar dapat mencegah radikalisme secara bersama-sama dan untuk hal tersebut maka ideologi Pancasila hadir menjadi sebuah ideologi yang mempersatukan. Setiap guru wajib memahami dan mengamalkan nilai-nilai dalam pancasila tanpa terkecuali.

Ciri umum radikalisme dalam sudut pandang agama tersebut sesuai dengan sejumlah ciri yang dikemukakan oleh Irwan Masduqi dalam (Muslihun :2018) dimana menyebutkan terdapat sejumlah ciri umum antara lain, (1) klaim kebenaran tunggal yang berlebihan; (2) mudah berburuk sangka terhadap orang diluar kelompoknya; (3) mudah mengkafirkan orang yang berbeda pendapat. Ciri radikalisme dalam sudut pandang agama tersebut lebih kepada pola pikir dan tindakan bukan hanya sebatas identitas atau pakaian.

Radikalisme dapat masuk ke dalam sekolah melalui dua cara dimana bahwa radikalisme dapat masuk melalui materi yang memiliki potensi mengandung paham radikal dan juga melalui penyampaian yang keliru. Bersumber dari sebuah jurnal dengan judul "Potensi Radikalisme Di Sekolah" yang ditulis oleh Moh. Hasim (2015) menyebutkan bahwa radikalisme merambah masuk kedalam dunia pendidikan salah satunya melalui sejumlah materi yang memiliki potensi unutk mendidik peserta didik menjadi intoleran jika tidak disampaikan dengan benar oleh guru. Dengan demikian guru memiliki peran penting dalam sebuah proses pembelajaran yang menolak pemahaman radikalisme yang berkembang dan harus berusaha mencegah paham radikal tersebut berkembang.

\section{Pelaksanaan Pembelajaran IPS Sebagai Bentuk Pencegahan Radikalisme}

Perencanaan merupakan salah satu tahap penting dalam proses pembelajaran dimana guru memaksimalkan potensi komponen pembelajaran yang ada. Pada tahap perencanaan, guru mempersiapkan sejumlah perangkat pembelajaran yang berguna untuk membuat pembelajaran lebih sistematis dan terstruktur. Perangkat tersebut antara lain, progam tahunan, progam semester, silabus, dan rencana pelaksanaan pembelajaran (RPP). RPP yang dibuat oleh guru juga mencakup mengenai sejumlah komponen pembelajaran antara lain, sumber belajar, metode pembelajaran dan media pembelajaran. Dengan demikian berarti guru IPS dalam pembelajaran IPS pada materi dinamika kependudukan sudah mempertimbangkan penggunaan sumber, metode, media yang mendasarkan atas kelebihan dan kekurangan, keadaan sekolah, dan kondisi peserta didik. Didalam perencanaan guru juga menyisipkan sejumlah nilai kakater, nilai-nilai karakter yang disisipkan didalam RPP antara lain karakter religius, nasionalis, dan integritas. Sementara karakter tersebut dapat diimplementasikan melalui sejumlah pembiasaan sikap seperti berdoa diawal pembelajaran, bersikap jujur dan disiplin, bekerja sama dengan peserta didik lain, bertanggung jawab, toleran, dsb.

Pelaksanaan pembelajaran merupakan proses yang diatur dan dilaksanakan sedemikian rupa berdasarkan langkah-langkah tertentu sehingga pelaksanaan pembelajaran mencapi hasil yang diharapkan. Didalam proses pelaksanaan pembelajaran guru melakukan beberapa tahap kegiatan antara lain, kegiatan pendahuluan/ kegiatan pembuka; kegiatan inti/penyampaian pembelajaran; dan kegiatan penutup/ menutup pembelajaran. Pada kegiatan pendahuluan dimana guru mengucapkan salam dan mengajak peserta didik untuk berdoa bersama menjadi salah satu bentuk implementasi dari karakter religius. Pada kegiatan inti dimana guru menggunakan metode ceramah yang memberikan kebebasan kepada guru untuk menyampaikan materi dan penguatan karakter yang dapat dikaitkan dengan materi juga menunjang dalam penguatan karakter itu sendiri. Sebagai contoh, didalam kegiatan inti dimana guru meminta peserta didik untuk melihat materi yang ada dibuku dan menanyakan mengenai pendapat peserta didik kemudian guru mengajak peserta didik untuk mengolah data melalui cara penyampaian langsung dan berpikir mengenai pentingnya toleransi dalam menyikapi keragaman budaya dan etnis di Indonesia pada subbab materi dinamika kependudukan. kegiatan penutup dimana guru menguatkan kembali karakter yang sebelumnya diajarkan melalui tanya jawab dan sejumlah penguatan. Pelaksanaan proses pembelajaran tersebut bertujuan untuk ketercapaian penguatan 
karakter yang sejalan dengan progam pemerintah berupa penguatan pendidikan karakter (PPK) yang diintegrasikan melalui kegiatan intrakulikuler. Ketercapaian tersebut diharapkan mampu menunjang pencegahan permasalahan sosial berupa degradasi moral, tawuran antar pelajar, hingga radikalisme.

Evaluasi sebagai sebuah proses mengumpulkan informasi tentang bekerjanya suatu hal dan kemudian informasi tersebut digunakan sebagai pertimbangan atau alternatif dalam pengambilan keputusan. Pelaksanaan evaluasi didalam pembelajaran IPS berfokus kepada ranah kognitif dan ranah penguatan karakter dimana dilakukan dengan sejumlah cara. Evaluasi dalam ranah kognitif dilakukan melalui kegiatan post test dimana menilai tingkat pemahaman peserta didik melalui sejumlah soal diakhir pembelajaran dan tanya jawab saat pembelajaran sementara untuk evaluasi dalam ranah penguatan karakter dilakukan dengan lembar penilaian sikap yang dimuat didalam RPP dan melalui kerjasama dengan pihak terkait.

\section{PEMBAHASAN}

Strategi sekolah dalam progam penguatan pendidikan karakter (PPK) dilakukan melalui visi misi yang dijabarkan sekolah yang menjadi identitas atau karakter sekolah dimana kemudian dicerminkan melalui sejumlah budaya sekolah dan kegiatan sekolah, menjawab tantangan mengenai radikalisme yang berkembang dimana sekolah merespon melalui visi, misi, budaya, dan kegiatan sekolah yang di cerminkan secara langsung oleh warga sekolah baik tenaga pendidik hingga peserta didik.

Pandangan guru mengenai radikalisme sendiri menafsirkan bahwa radikalisme tidak selalu berkaitan dengan konteks keagamaan, dimana radikalisme sendiri dapat dipandang secara politis maupun terminologis, terkait ciri umum radikalisme lebih kepada pola pikir intoleran dan tidak menghargai pendapat orang yang berbeda bahkan mudah menjustifikasi atau mengkafirkan orang yang tidak sejalan dalam ibadahnya. Terakhir, radikalisme dapat menyusup kedalam lembaga pendidikan melalui berbagai cara, dua diantaranya antara lain melalui materi yang berpotensi menimbulkan pola pikir radikal dan melalui penyampaian materi yang keliru.

Pelaksanaan pembelajaran IPS dalam upaya pencegahan radikalisme dapat dilaksanakan melalui penyisipan budaya sekolah maupun karakter yang terdapat didalam progam penguatan pendidikan karakter (PPK) dimana pengintegrasian progam tersebut dapat dilihat melalui tiga tahap pembelajaran yaitu tahap perencanaan, tahap pelaksanaan, dan tahap evaluasi. Pada tahap perencanaan dapat dilihat melalui perangkat pembelajaran seperti rencana pelaksanaan pembelajaran (RPP); pada tahap pelaksanaan dapat dilihat melalui cara guru dalam penyampaian pembelajaran, interaksi yang terjadi, dan respon peserta didik; terakhir pada tahap evaluasi pengintegrasian PPK dapat dilihat melalui lembar penilaian sikap yang termuat di dalam RPP, melalui pengamatan langsung, melalui pihak terkait seperti wali kelas, guru BK, pembina pondok, dan wali murid.

\section{SIMPULAN}

Upaya sekolah dalam mencegah radikalisme merambah didalam sekolah adalah melalui integrasi nilai-nilai PPK dan penguatan karakter termasuk karakter yang menjadi budaya sekolah kedalam kegiatan ekstrakulikuler dan kegiatan intrakulikuler salah satunya berupa pembelajaran IPS. Pencegahan radikalisme melalui kegiatan ekstrakulikuler dirasa sudah optimal dikarenakan dibimbing langsung oleh guru dan kegiatan yang dilaksanakan lebih menekankan pada peran aktif peserta didik. Sementara pencegahan radikalisme melalui kegiatan pembelajaran berupa pembelajaran IPS dirasa belum maksimal dikarenakan perlu menyesesuaikan dengan materi dan disamping itu perlu adanya saling keterkaitan antara mata pelajaran lainnya sehingga beban penguatan karakter tidak hanya berfokus pada mata pelajaran tertentu. Dalam pelaksanaan pencegahan radikalisme melalui kegiatan intrakulikuler dan ekstrakulikuler pada tahun ajaran 2020/2021 terkendala dengan adanya pandemi Covid-19 dimana dengan adanya pandemi tersebut menyebabkan sejumlah kegiatan ekstrakulikuler tidak dapat dilaksanakan dan dalam kegiatan intrakulikuler juga terkendala dimana dilakukan secara daring dengan waktu yang terbatas dengan jumlah mata pelajaran yang banyak baik mata pelajaran lokal dan mata pelajaran umum, sementara untuk pembelajaran tatap muka perlu menyesuaikan dengan protokol kesehatan sehingga tidak dapat seoptimal seperti sebelum adanya pandemi. 


\section{DAFTAR PUSTAKA}

Aan Komariah, dan Cepi. 2010. Visionary Leadership Menuju Sekolah Efektif. Jakarta : PT Bumi Aksara

Asrori, Ahmad. 2015. Radikalisme Di Indonesia: Antara Historisitas dan Antropisitas. Kalam: Jurnal Agama dan Pemikiran, Volume 9, Nomor 2

Indonesia. 2003. Undang-Undang Nomor 20 Tahun 2003 tentang Sistem Pendidikan Nasional. Lembaran Negara RI Tahun 2003. Jakarta: Sekertariat Negara

Indonesia. 2009. Undang-Undang Nomor 39 Tahun 2009 tantang Pemenuhan Beban Kerja Guru Dan Pengawas Satuan Pendidikan. Lembaran Negara RI Tahun 2009. Jakarta: Sekertariat Negara
Indonesia. 2017. Peraturan Presiden Nomor 87 Tahun 2017 tentang Penguatan Pendidikan Karakter. Lembaran Negara RI Tahun 2017 Nomor 195. Jakarta : Sekertariat Negara.

Moh., Hasim. 2015. Potensi Radikalisme Di Sekolah Studi Terhadap Buku Pendidikan Agama Islam Sekolah Dasar. EDUKASI : Jurnal Pendidikan Agama dan Keagamaan, Volume 13, Nomor 2

Muslihun. 2018. Dakwah dan Radikalisme[Tesis]. Surabaya : Universitas Islam Negeri Sunan Ampel.

Sugiyono. 2016. Metode Penelitian Kuantitatif, Kualitatif dan R\&D. Bandung : PT Alfabeta 